\title{
BMJ Open Prevalence, care-seeking practices and impact of self-reported vision impairment in Southwest Cameroon: a community-based study
}

\author{
Susan N Mbeboh, ${ }^{1}$ Sabrinah Ariane Christie, ${ }^{2}$ Melissa Carvalho, ${ }^{3}$ Drusia Dickson, ${ }^{2}$ \\ Theophile Nana, ${ }^{4}$ Frida Embolo, ${ }^{1}$ Rochelle Dicker, ${ }^{3}$ Catherine Juillard (D) , ${ }^{3}$ \\ Alain Chichom Mefire ${ }^{1}$
}

To cite: Mbeboh SN, Christie SA, Carvalho M, et al. Prevalence, care-seeking practices and impact of self-reported vision impairment in Southwest Cameroon: a communitybased study. BMJ Open 2020;10:e041367. doi:10.1136/ bmjopen-2020-041367

- Prepublication history and additional material for this paper is available online. To view these files, please visit the journal online (http://dx.doi.org/10. 1136/bmjopen-2020-041367)

Received 05 June 2020 Revised 15 0ctober 2020 Accepted 04 November 2020

Check for updates

(C) Author(s) (or their employer(s)) 2020. Re-use permitted under CC BY-NC. No commercial re-use. See rights and permissions. Published by BMJ.

${ }^{1}$ Faculty of Health Sciences, University of Buea, Buea, Cameroon

${ }^{2}$ Department of Surgery, University of California San Francisco, San Francisco, California, USA

${ }^{3}$ Department of Surgery, University of California Los Angeles, Los Angeles, California, USA

${ }^{4}$ Department of Surgery, Limbe Regional Hospital, Limbe, Cameroon

Correspondence to Dr Catherine Juillard; c.juillard@gmail.com

\section{ABSTRACT}

Objectives To establish the prevalence of self-reported vision impairment $(\mathrm{VI})$ in Southwest Cameroon and describe associated care-seeking practices, functional limitations and economic hardships.

Design A three-stage clustered sampling household community-based survey.

Setting The Southwest region of Cameroon.

Participants 8046 individuals of all ages residing in the Southwest region of Cameroon.

Primary and secondary outcome measures Prevalence of self-reported $\mathrm{Vl}$, onset of vision loss, care-seeking practices, diagnosis and treatment, functional limitations, economic hardships on household, beliefs about surgical treatability of blindness and barriers to surgical care. Results The estimated prevalence of self-reported VI in Southwest Cameroon was $0.87 \%(95 \% \mathrm{Cl} 0.62$ to 1.21$)$. Among participants aged $\geq 40$ years, the prevalence increased to $2.61 \%$ (95\% $\mathrm{Cl} 1.74$ to 3.90$)$. Less than a quarter of affected participants reported difficulty working $(20.5 \%)$ or trouble going to school $(12.0 \%)$ as a result of their VI. Yet, over half $(52 \%, n=43)$ of affected households experienced significant economic hardships due to the VI. Residing in an urban setting (aOR 1.16, 95\% Cl 1.04 to 1.30) and belonging to a higher socioeconomic status (aOR $1.13,95 \% \mathrm{Cl} 1.02$ to 1.26 ) were factors associated with the belief that certain types of blindness were surgically reversible. Formal care was not sought by $16.3 \%(n=8)$ of affected participants. Cataracts was the leading diagnosis among participants who did seek formal care $(43.2 \%$, $n=16$ ), although $93.8 \%$ of these cases were not surgically treated, primarily due to a lack of perceived need.

Conclusion The prevalence of individuals who report vision impairment in Southwest Cameroon is considerably lower than prior published estimates based on visual physical examinations. Routine community-level screening and cost financing schemes could improve detection of pre-clinical eye disease and the utilisation of surgical care. It could also pre-empt disability and economic hardships associated with advanced $\mathrm{VI}$ in the region.

\section{INTRODUCTION}

Vision impairment (VI) is the functional limitation of the visual system, as a result of a
Strengths and limitations of this study

- This was a community-based household survey of the Southwest region of Cameroon that employed a three-stage cluster sampling framework.

- Demographic, socioeconomic and behavioural data of over 8000 study participants were collected.

- At times, only the designated family representative provided information on behalf of all household members in each sampled household.

- This may have led to an under-reporting of cases and their associated care-seeking behaviours and functional impairments.

disease or disorder, which interferes with an individual's ability to perform daily activities. ${ }^{1}$ Globally, an estimated 253 million people are visually impaired, among which 36 million are blind and 217 million have moderate to severe vision loss. ${ }^{2}$ The loss of vision presents significant consequences to an individual, increasing the risk of death, adversely affecting quality of life, and considerably impeding economic and educational opportunities. ${ }^{3} \mathrm{VI}$ is a major global public health issue, particularly in low-income and middleincome countries (LMICs) where a majority of the world's vision impaired are found. ${ }^{4}$

The WHO estimates that $80 \%$ of VI is curable or preventable. ${ }^{15}$ Surgically reversible causes of vision loss, such as cataracts, are particularly prevalent in LMICs and contribute to significant disability. Cataracts account for $48 \%$ of all VI worldwide and are the leading cause of blindness in LMICs. ${ }^{6}$ Cataract surgery can be feasibly provided in LMICs; it is the second most cost-effective health intervention after vaccinations. ${ }^{78}$ Several studies in LMIC settings have also highlighted its positive impact on improving patients' autonomy and productivity. ${ }^{8-11}$ 
Despite their treatability, many people in LMICs still live with surgically reversible eye conditions. Health system strengthening and sustainable healthcare financing measures are needed to address low surgical coverage and poor utilisation of eye care services. ${ }^{12-14}$ There is also a critical knowledge gap on strategies to expand treatment of surgically reversible VI, particularly in sub-Saharan Africa (SSA) where the lowest cataract surgical rates are reported. ${ }^{12}$

To eradicate surgically reversible VI, we need an understanding of the care-seeking patterns of persons experiencing vision loss in the community and their commonly held beliefs about the surgical treatment of blindness. Most community-based studies of surgically reversible blindness in SSA have focused on establishing the prevalence of VI via direct physical examinations, but have largely overlooked perceived impairment and functional disability criteria. ${ }^{15-18}$ Investigating these factors, however, would provide key information on barriers to care and could effectively guide policy to promote the utilisation of surgical services. To our knowledge, no surveys investigating care-seeking behaviours among persons reporting a VI had thus far been carried out in the Central African country of Cameroon. This study aimed to establish the prevalence and patterns of self-reported VI in the Southwest region of Cameroon, and describe functional limitations, economic hardships and care-seeking practices in this population. We hypothesised that this population likely experiences significant disability from their vision loss and may represent a critical group to engage in care.

\section{MATERIALS AND METHODS}

\section{Study design and setting}

This study was designed as a subanalysis of a broader crosssectional community-based survey on injury and unmet surgical need in Southwest Cameroon. ${ }^{19}$ It followed the STROBE cross-sectional reporting guidelines. ${ }^{20}$

The Southwest region is one of two predominantly Anglophone-speaking areas in Cameroon. It is composed of 18 health districts, 36 health areas and had an estimated population of 1575224 in $2016 .^{2122}$

\section{Study population}

The target population consisted of all individuals residing in Southwest Cameroon. Household members living in each surveyed household were included in the study population. Households without an eligible family representative (aged $\geq 18$ years) present or those that denied consent were excluded from the study.

\section{Sampling method}

Enumeration areas were selected using a three-stage cluster sampling framework. Clusters of nine health districts and four health areas per district were selected using a probability proportionate to size. Two health districts (Akwaya and Bakassi) were excluded from the sampling framework due to security concerns. Following the selection of clusters at the first two sampling levels, a starting point was randomly selected in each sampled health area using geolocation data. Data collection commenced at the closest settlement to this starting point. Households were approached contiguously and circumferentially until a target sample size of 200 households per cluster was attained. To prevent bias, households without an eligible family representative present were approached at least twice.

\section{Sample size calculations}

The sample size for the community-based survey, in which this subanalysis was nested, was calculated to provide $78 \%$ power to detect a $6 \%$ yearly incidence of injury (based on prior population-based surveys in Sub-Saharan Africa). ${ }^{23} 24$ We conducted an additional sample size calculation using a $11.2 \%$ prevalence of self-reported visual difficulty in South Africa to verify that our sample was large enough for our subanalysis. ${ }^{25}$ This subcalculation used a precision level of $\pm 1 \%, 95 \%$ CI and design effect of 2 to account for the multicluster sampling framework. A minimum sample size of 7623 was generated.

\section{Study questionnaire development}

We adapted our study questionnaire from the Surgeons OverSeas Assessment of Surgical Needs (SOSAS) version 3.0. The SOSAS tool is a household survey designed to measure unmet surgical need in the community. ${ }^{26}$ It has been validated in multiple LMIC settings, ${ }^{26}{ }^{27}$ and demonstrated a $94.6 \%$ correlation between self-reports of vision loss using this survey and results of visual physical examinations. ${ }^{28}$ Our questionnaire was reviewed internally by a panel of US and Cameroonian clinicians for its relevance and subsequently piloted for suitability in Buea, located in Southwest Cameroon. The questionnaire was modified based on feedback obtained during this process.

\section{Training of survey team}

A survey team of eight medical and master's level students and a practicing physician were trained on the research protocol and questionnaire, and took an online course on human subjects training to meet HIPAA compliance requirements. Prior to data collection, each survey team member practised simulated exercises in front of study investigators to evaluate their interactions with participants. Those demonstrating proficiency were cleared to proceed with data collection activities.

\section{Data collection}

Data collection occurred over an 8-week period, between 3 January and 3 March 2017. Each target household designated a family representative who was approached for consent using a standard oral consent script. If granted, members of the survey team verbally administered the questionnaire to the representative who enumerated and provided information on all members of the household. Data collected included demographic and socioeconomic indicators. The type of cooking fuel used by the household served as a marker of socioeconomic status (SES) since liquid petroleum gas (LPG), as opposed to wood, correlates with a higher SES in the Cameroonian context. $^{29-31}$ 
Vision impairment in this study was defined as total or partial blindness and low vision that cannot be corrected by visual aids. To identify persons with a VI, family representatives were asked if any member of their household was totally blind or had significant difficulty seeing. Households reporting a member with total blindness or significant vision loss (partial blindness or low vision not corrected by visual aids) were asked to provide additional information on the onset of vision loss, care-seeking practices, diagnosis and treatment, barriers to care, functional limitations and economic hardships associated with the VI. Visually impaired household members, if present and not a minor, directly reported this information to the survey team. Lastly, family representatives were surveyed on the household's belief about the surgical treatability of certain types of blindness (online supplemental table A).

\section{Data management and analysis}

Data were stored and manually entered into REDCap, an encrypted online database. ${ }^{32}$ Statistical analyses were conducted using Stata V.14 and adjusted as appropriate for the clustered sampling framework using the suy command. ${ }^{33}$ Descriptive statistics, including frequencies, proportions, medians and means, were generated. Groups were compared using the adjusted Wald and Pearson $\chi^{2}$ tests as appropriate. Missing data were excluded from analyses, and statistical significance was set at a $\mathrm{P}$ value of 0.05 . Factors associated with self-reported VI and the belief that certain types of blindness can be surgically corrected were identified through univariate and multivariable analyses. A multivariable logistic regression model was built using demographic variables, spoken language in the household and at health facilities, and socioeconomic indicators. These variables were selected based prior literature investigating VI risk factors in LMICs. Variables included in the final model were determined using a backward stepwise regression procedure. These covariates consisted of the following: age, urban household setting, use of LPG as a cooking fuel and the highest education level achieved by a member of the household.

\section{Patient and public involvement}

Patients or the public were not involved in the design, or conduct, or reporting, or dissemination plans of our research. The development of the research question and outcome measures were informed by the need to fill in critical knowledge gaps and target difficult to access populations who fail to present to care. The study results are available to all participants on request.

\section{RESULTS}

\section{Characteristics of households and the study population}

We approached 1551 households of which 1287 (83\%) consented to participate in the study. Individual data on 8046 participants were collected from consenting households. The median age of the study population was 20 years (IQR 10-34); over half were female $(52 \%, \mathrm{n}=4181)$. Most households reported at least one member achieving a tertiary-level $(39.7 \%, \mathrm{n}=3133)$ or secondary-level $(37.4 \%, \mathrm{n}=2955)$ education. The vast majority of households were located in a rural setting $(70.7 \%, \mathrm{n}=5620)$.

\section{Prevalence of VI and associated sociodemographic factors}

Eighty-three participants reported conditions of total blindness $(44.6 \%, \mathrm{n}=37)$ or significant vision loss $(55.4 \%$, $\mathrm{n}=46$ ). The overall prevalence of self-reported VI in the study population was $0.87 \%$ (95\% CI 0.62 to 1.21 ). This prevalence increased to $2.61 \%$ (95\% CI 1.74 to 3.90 ) when restricting the study population to individuals aged $\geq 40$ years. Participants with a self-reported VI were significantly older than participants with no VI $(\mathrm{p}<0.01)$. Moreover, they were less likely to use LPG $(p<0.01)$ as a source of cooking fuel-a marker of higher SES. There were no significant differences between participants with a selfreported VI and the remaining study population based on sex and highest education level achieved by a household member (table 1).

A multivariable logistic regression analysis identified older age as a significant predictor of a self-reported VI (aOR 1.06, 95\% CI 1.04 to 1.07). The use of LPG as a cooking fuel in the household was associated with lower odds of reporting a VI (aOR $0.35,95 \%$ CI 0.19 to 0.64$)$. Furthermore, residing in an urban setting (aOR 1.16) and using LPG as a cooking fuel (aOR 1.13) were factors associated with a household's belief that certain types of blindness were surgically reversible (table 2 ).

\section{Onset of vision loss, functional limitations and economic hardships}

Most participants developed their VI slowly over time $(69.6 \%, \mathrm{n}=55)$; a minority developed their condition suddenly $(7.6 \%, \mathrm{n}=6)$. Others were born with their condition $(8.9 \%, \mathrm{n}=7)$ or developed it following an injury $(8.9 \%, \mathrm{n}=7)$. The mean vision loss duration among affected participants was 9.1 years $(\mathrm{SD} \pm 8.6)$.

A majority of participants with a self-reported VI $(91.6 \%, \mathrm{n}=76)$ cited at least one functional limitation due to their vision loss. Most commonly reported were difficulty working $(20.5 \%)$; trouble going to school (12.0\%); trouble interacting with others, shopping or travelling $(10.8 \%)$; and feeling ashamed or depressed $(7.2 \%)$. Moreover, $52 \%(n=43)$ of participants reporting a VI noted that their condition had an economic impact on their households, primarily due to their families' spending assets, savings or having to borrow money $(48.8 \%)$, or their households earning less money as a result of a subject's vision loss (34.9\%) (table 3).

\section{Care-seeking practices and barriers to surgery}

Approximately $81.9 \% \quad(n=68)$ of participants with a selfreported VI sought formal care. Among participants who provided information about their care-seeking practices $(n=49), 16.3 \% \quad(n=8)$ did not seek treatment for their condition. Others first sought care from alternative sources $(n=6)$, including traditional medicine and home treatment from family or friends (figure 1). Participants 
Table 1 Socioeconomic comparisons of study participants by reported vision impairment status $(n=8046)$

\begin{tabular}{|c|c|c|c|}
\hline Characteristics & $V l^{a}(n=83)$ & No VI $(n=7963)$ & $P$ value \\
\hline Age (mean $(95 \% \mathrm{Cl}))$ & 55 (47 to 63 ) & 23 (23 to 24$)$ & $<0.001^{*}$ \\
\hline Sex & & & 0.275 \\
\hline Female & $49(59.0 \%)$ & $4132(51.9 \%)$ & \\
\hline Household possesses a cell phone & $77(93.0 \%)$ & $7438(93.4 \%)$ & 0.518 \\
\hline No formal school-based education & $1(1.3 \%)$ & $156(2.0 \%)$ & \\
\hline Primary-level education & $16(20.3 \%)$ & $1631(20.5 \%)$ & \\
\hline Secondary-level education & $38(48.1 \%)$ & $2917(36.6 \%)$ & \\
\hline Tertiary-level education & $24(30.4 \%)$ & 3109 (39.0\%) & \\
\hline Household setting & & & 0.570 \\
\hline Wood & $81(97.6 \%)$ & $7325(92.0 \%)$ & 0.079 \\
\hline Charcoal & $4(4.8 \%)$ & $1274(16.0 \%)$ & $0.016^{\star \star}$ \\
\hline Kerosene & $7(8.4 \%)$ & $1279(16.1 \%)$ & 0.05 \\
\hline Liquid petroleum gas (LPG) & $16(19.3 \%)$ & $3432(43.1 \%)$ & $0.004^{\star *}$ \\
\hline Household owns agricultural land & $54(65.1 \%)$ & $5111(64.2 \%)$ & 0.866 \\
\hline Household owns/rents/lives for free in residence & & & 0.318 \\
\hline Own & $66(79.52)$ & $5001(63.41)$ & \\
\hline Rent & $11(13.25)$ & $1999(25.35)$ & \\
\hline Live for free & $6(7.23)$ & $887(11.25)$ & \\
\hline
\end{tabular}

${ }^{*}$ Represents a $p$ value of $\leq 0.05$; percentages based on non-missing values.

$\mathrm{VI}$, visual impairment.

cited the high cost of medical care $(52.9 \%, \mathrm{n}=9)$, their perceptions that their VI was not serious $(23.5 \%, \mathrm{n}=4)$, their personal preference $(17.7 \%, \mathrm{n}=4)$ and a lack of awareness that their VI could be treated $(5.9 \%, \mathrm{n}=1)$ as reasons for not first seeking formal care.

Over two-thirds of participants who sought formal care received a diagnosis $(67.6 \%, \mathrm{n}=46)$. Among participants who could recall their diagnosis, most reported a diagnosis of cataracts $(43.2 \%, \mathrm{n}=16)$, followed by glaucoma $(6.2 \%$, $\mathrm{n}=6)$, filariasis $(5.4 \%, \mathrm{n}=2)$ and the presence of a foreign body $(5.4 \%, \mathrm{n}=2)$. The vast majority of participants had not obtained surgical treatment after seeking formal care $(95.4 \%, \mathrm{n}=63)$, including $93.8 \%(\mathrm{n}=15)$ of reported cataract cases, the primary reasons being a lack of perceived need $(43.4 \%, \mathrm{n}=36)$ and finances to afford surgery $(14.5 \%, \mathrm{n}=12)$ (figure 2).

\section{DISCUSSION}

This study investigated the prevalence and care-seeking practices of persons reporting a VI in Southwest Cameroon. It also described the functioning and economic impact

\begin{tabular}{|c|c|c|c|c|}
\hline Variable & Unadjusted OR & $(95 \% \mathrm{Cl})$ & Adjusted OR† & $(95 \% \mathrm{Cl})$ \\
\hline Age & 1.00 & 0.998 to 1.003 & 1.00 & 0.998 to 1.00 \\
\hline Urban household setting & 1.17 & 1.048 to 1.298 & $1.16^{*}$ & 1.037 to 1.303 \\
\hline Use of $L P G$ as cooking fuel & 1.18 & 1.068 to 1.297 & $1.13^{*}$ & 1.022 to 1.259 \\
\hline $\begin{array}{l}\text { Highest education level achieved by any } \\
\text { household member }\end{array}$ & 1.00 & 0.993 to 1.016 & 1.00 & 0.991 to 1.014 \\
\hline
\end{tabular}

${ }^{*}$ An asterisk represents a significant OR.

TORs were adjusted for age, urban residence, use of LPG as a cooking fuel and highest education level achieved by a member of the household. 
Table 3 Functional limitations and economic hardships associated with a reported $\mathrm{VI}$

\begin{tabular}{lc}
\hline Functional limitations (n=83) & $\mathbf{N}(\%)$ \\
\hline Difficulty working/working in the home & $17(20.5)$ \\
\hline Trouble going to school & $10(12.0)$ \\
\hline $\begin{array}{l}\text { Trouble interacting with others, shopping, } \\
\text { travelling }\end{array}$ & $9(10.8)$ \\
\hline $\begin{array}{l}\text { Feeling ashamed or depressed } \\
\text { Needing assistance dressing, eating or } \\
\text { toileting }\end{array}$ & $6(7.2)$ \\
\hline $\begin{array}{l}\text { Difficulty standing or walking or sitting } \\
\text { Difficulty picking things up or using arms or }\end{array}$ & $4(4.8)$ \\
hands & $1(1.20)$ \\
\hline $\begin{array}{l}\text { Household's economic hardships (n=43) } \\
\text { Family has spent assets/savings or borrowed } \\
\text { money }\end{array}$ & $\mathbf{N}(\%)$ \\
\hline $\begin{array}{l}\text { Family earns less money } \\
\text { Family members psychologically affected }\end{array}$ & $9(20.9)$ \\
\hline $\begin{array}{l}\text { Person with visual impairment requires } \\
\text { caretaker from the household }\end{array}$ & $8(18.6)$ \\
\hline \begin{tabular}{l} 
Harder to afford necessities like food and rent \\
\hline
\end{tabular} & $3(7.0)$ \\
\hline
\end{tabular}

VI, visual impairment.

of VI as a means of understanding barriers to surgical care utilisation. The study found a $0.87 \%$ prevalence of self-reported VI in the region. Although this prevalence increased to $2.61 \%$ among high-risk individuals (aged 40 years or older), it was still considerably lower than prior estimates of VI in the region based on visual physical examinations (10.2\% in Muyuka district, $4.4 \%$ in Limbe). ${ }^{1617}$ The discrepancy between prevalence estimates of reported versus examination-detected VI has important implications for policy improvements in Southwest Cameroon. It suggests that a substantial proportion of individuals harbouring progressive eye disorders may

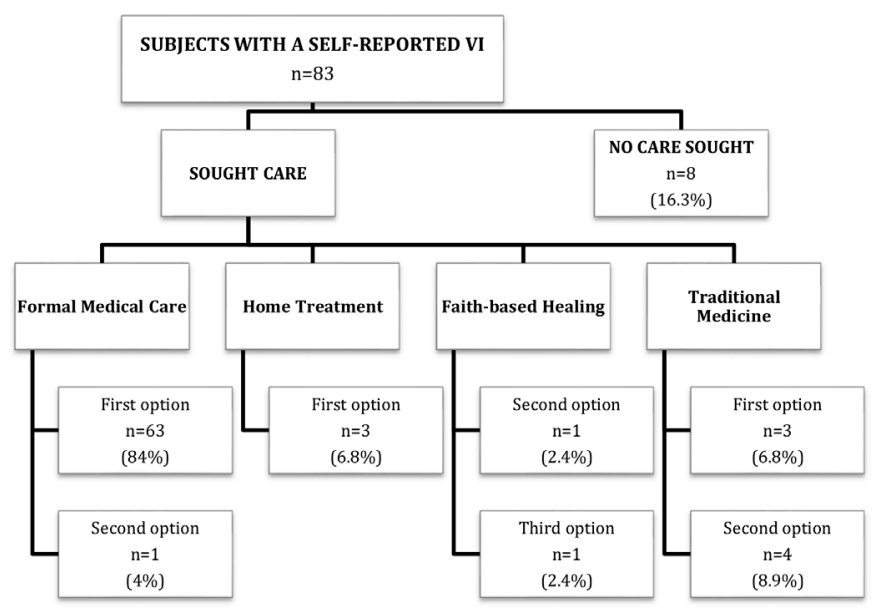

Figure 1 Care-seeking practices among study subjects with a perceived vision impairment (VI). Percentages based on non-missing values. not be aware of their visual problems. It also highlights a critical role for routine screening to detect pre-clinical eye disease and pre-empt disability associated with more advanced VI.

Participants who reported a VI were more likely to belong to households of lower SES, corroborating prior evidence linking poverty to blindness. ${ }^{34}{ }^{35}$ Moreover, being of a higher SES and residing in an urban setting were predictive factors of a participants' belief that certain blindness were surgically reversible. These findings raise concerns about socioeconomic disparities in access to eye health education and services in the region. Indeed, economic analyses have demonstrated that the use of fee-for-service in Cameroon has created an inequitable health system where access to care is largely dependent on income. Moreover, the distribution of health providers in Cameroon is largely concentrated in urban settings, which has resulted in disparities in health outcomes between socioeconomic groups in rural and urban areas. ${ }^{36}$ Although this study does not specifically investigate sources of health information, identifying where people receive health information, particularly rural populations, could help develop effective strategies for disseminating eye health education across Southwest Cameroon.

Our findings also revealed low surgical care utilisation among participants with a self-reported VI. Over 90\% of reported cataract cases were not surgically treated, despite surgery being a highly effective intervention to recover vision loss from this condition. ${ }^{7}$ Surgery is especially recommended when the patient's VI detrimentally affects their quality of life. Though most affected participants reported at least one limitation as a result of their VI, this deficit may not have had a major impact on their functioning. For instance, less than a quarter of affected participants revealed difficulty working or going to school. These results could imply that many participants with a self-reported VI may not be experiencing significant enough functional limitations compelling them to obtain surgical treatment. Indeed, $43 \%$ of participants reporting a VI did not perceive a need for surgery. This perception along with the high cost of care were the most significant barriers to obtaining surgical care, which suggests that competing priorities and limited disposable income may influence people's decisions to prioritise surgical treatment. This is particularly relevant if they do not perceive their VI to have a major impact on their dayto-day activities.

The high cost of care placed a significant economic burden on households with a visually impaired member, as nearly half of these families reported having to spend assets or borrow money to treat the member's condition. The absence of universal health coverage and cost financing schemes prevent many in LMICs from accessing needed surgical treatment. ${ }^{37}$ Cost restructuring mechanisms are thus critically needed to make eye care services more accessible to populations in Cameroon. The Cameroonian government should engage with the 


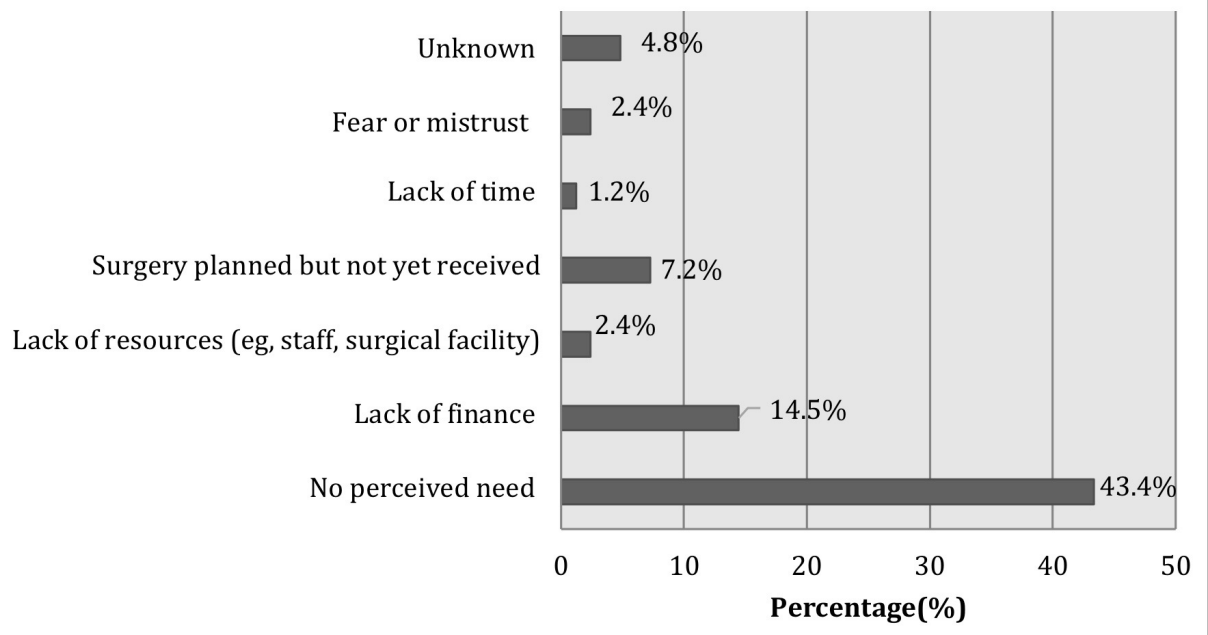

Figure 2 Barriers to obtaining surgery among subjects with a perceived vision impairment.

private sector and international donors to prioritise and scale up surgical capacity in the country, particularly in rural areas. Adapting the Aravind model of eye care to the Cameroonian setting could be a potential solution to meet the current demand for cataract surgery. This social enterprise model enables the provision of cataract surgeries to the poor at low or no cost by relying on crosssubsidisation schemes and a high volume of services. A new hospital in Cameroon (The Magrabi ICO Cameroon Eye Institute) was recently allocated a cataract bond to establish the Aravind model of care ${ }^{38}$ There is thus an opportunity for future studies to investigate whether this model of care is replicable and sustainable in the subSaharan African context.

\section{Limitations}

A number of limitations should be noted. Data were at times only collected from one designated representative in each sampled household who provided information on behalf of all other household members. This representative may not have always been aware of every aspect influencing a subject's care-seeking behaviour, as it would depend on the household dynamics and the relationship that particular respondent had with other members of the household. Thus, the prevalence of reported VI and its impact on functioning could have been underestimated. Future population-based surveys relying on self-reports should preferably collect data directly from individual participants to ensure greater accuracy and completeness of information about patterns of vision loss, beliefs and practices. Findings for this study are specific to the Southwest region, and may not be generalisable to other areas of Cameroon and sub-Saharan Africa.

\section{CONCLUSION}

The prevalence of self-reported VI in Southwest Cameroon is lower than examination-based estimates of visual deficits, underscoring the need for routine screening at the community level to pre-empt disability. Although self-reported VI did not significantly impact functioning among affected individuals, it was associated with economic hardships on their households. Surgical treatment among participants reporting a VI was low, primarily due to the prohibitive cost of care and the perception that surgery was not necessary. Cost restructuring mechanisms and eye health education are critically needed to improve surgical care utilisation in the region, particularly among populations in rural and low-income households. Health promotion approaches should specifically target patients at risk of opting out of care, ensuring they understand the benefits of surgery in reversing visions loss and reducing disability.

Acknowledgements We wish to acknowledge the following individuals for their dedicated work and invaluable contribution to the implementation of this study: $\mathrm{Dr}$ Alain Etoundi Mballa MD from the Cameroonian Ministry of Public Health; Kareen Azemfac MD, Emerson Wepngong MD, William Chendjou MD, Eunice Oben MD, Dr Victor Mbome MD and Dr Pius Ekumbu PhD from the University of Buea, Faculty of Health Sciences; and finally the directors and staff of the Limbe Regional Hospital.

Contributors SAC and CJ conceived and designed the study. SNM, SAC, DD, TN and $\mathrm{FE}$ were responsible for the acquisition of the data, under the supervision and support of ACM, RD and CJ. SAC analysed the data, and SNM, SAC and MC interpreted the data. SNM and MC drafted the manuscript, with critical revisions from SAC, DD, TN, FE, ACM, RD and CJ. All authors have given their final approval and agree to be accountable for all aspects of the work.

Funding This work was supported by the Association for Academic Surgery/ Association for Academic Surgery Foundation Global Surgery Research Fellowship Award (no award/grant number provided).

Competing interests None declared.

Patient consent for publication Not required.

Ethics approval Approval for this study was granted by the Institutional Review Boards of the University of Douala and the University of California, San Francisco.

Provenance and peer review Not commissioned; externally peer reviewed.

Data availability statement Data are available on reasonable request.

Supplemental material This content has been supplied by the author(s). It has not been vetted by BMJ Publishing Group Limited (BMJ) and may not have been peer-reviewed. Any opinions or recommendations discussed are solely those of the author(s) and are not endorsed by BMJ. BMJ disclaims all liability and responsibility arising from any reliance placed on the content. Where the content 
includes any translated material, BMJ does not warrant the accuracy and reliability of the translations (including but not limited to local regulations, clinical guidelines, terminology, drug names and drug dosages), and is not responsible for any error and/or omissions arising from translation and adaptation or otherwise.

Open access This is an open access article distributed in accordance with the Creative Commons Attribution Non Commercial (CC BY-NC 4.0) license, which permits others to distribute, remix, adapt, build upon this work non-commercially, and license their derivative works on different terms, provided the original work is properly cited, appropriate credit is given, any changes made indicated, and the use is non-commercial. See: http://creativecommons.org/licenses/by-nc/4.0/.

\section{ORCID iD}

Catherine Juillard http://orcid.org/0000-0003-0847-8933

\section{REFERENCES}

1 Freeman KF, Cole RG, Faye EE, et al. Optometric clinical practice guideline: care of the patient with visual impairment (low vision rehabilitation). Louis, MO: American Optometric Association, 1997.

2 Vision impairment and blindness. WHO Fact Sheet. World Health Organization, 2017. Available: www.who.int/mediacentre/factsheets/ fs282/en/ [Accessed 4 Dec 2017].

3 Bourne RRA, Flaxman SR, Braithwaite T, et al. Magnitude, temporal trends, and projections of the global prevalence of blindness and distance and near vision impairment: a systematic review and metaanalysis. Lancet Glob Health 2017;5:e888-97.

4 Pizzarello L, Abiose A, Ffytche T, et al. Vision 2020: the right to sight: a global initiative to eliminate avoidable blindness. Arch Ophthalmol 2004;122:615-20.

5 Congdon NG, Friedman DS, Lietman T. Important causes of visual impairment in the world today. JAMA 2003;290:2057-60.

6 World Health Organization. WHO Fact Sheet. Causes of blindness and vision impairment, 2017. Available: http://www.who.int/ blindness/causes/en/ [Accessed 4 Dec 2017].

7 Khandekar R, Sudhan A, Jain BK, et al. Impact of cataract surgery in reducing visual impairment: a review. Middle East Afr J Ophthalmol 2015;22:80.

8 Grimes CE, Henry JA, Maraka J, et al. Cost-effectiveness of surgery in low- and middle-income countries: a systematic review. World $J$ Surg 2014;38:252-63.

9 Finger RP, Kupitz DG, Fenwick E, et al. The impact of successful cataract surgery on quality of life, household income and social status in South India. PLoS One 2012;7:e44268.

10 Lamoureux EL, Fenwick E, Pesudovs K, et al. The impact of cataract surgery on quality of life. Curr Opin Ophthalmol 2011;22:19-27.

11 Desai P, Reidy A, Minassian DC, et al. Gains from cataract surgery: visual function and quality of life. Br J Ophthalmol 1996;80:868-73.

12 Tabin G, Chen M, Espandar L. Cataract surgery for the developing world. Curr Opin Ophthalmol 2008;19:55-9.

13 Khanna R, Pujari S, Sangwan V. Cataract surgery in developing countries. Curr Opin Ophthalmol 2011;22:10-14

14 Aboobaker S, Courtright P. Barriers to cataract surgery in Africa: a systematic review. Middle East Afr J Ophthalmol 2016;23:145.

15 Naidoo K, Gichuhi S, Basáñez MG, et al. Prevalence and causes of vision loss in sub-Saharan Africa: 1990-2010. Br J Ophthalmol 2014.

16 Oye JE, Kuper H, Dineen B, et al. Prevalence and causes of blindness and visual impairment in Muyuka: a rural health district in South West Province, Cameroon. Br J Ophthalmol 2006;90:538-42.

17 Oye JE, Kuper H. Prevalence and causes of blindness and visual impairment in Limbe urban area, South West Province, Cameroon. $\mathrm{Br}$ J Ophthalmol 2007;91:1435-9.
18 Oye J, Mactaggart I, Polack S, et al. Prevalence and causes of visual impairment in Fundong district, North West Cameroon: results of a population-based survey. Ophthalmic Epidemiol 2017;24:394-400.

19 Christie SA, Dickson D, Mbeboh SN, et al. Association of health care use and economic outcomes after injury in Cameroon. JAMA Netw Open 2020;3:e205171.

20 von Elm E, Altman DG, Egger M, et al. The strengthening the reporting of observational studies in epidemiology (STROBE) statement: guidelines for reporting observational studies. Epidemiology 2007;18:800-4.

21 Demographiques I. Etat et Structures de la Population - Indicateurs Démographiques, 2010.

22 Institut National de la Statistique (INS) and ICF International.. Enquête Démographique et de Santé et Indicateurs Multiples du Cameroun 2011. Calverton, Maryland, USA: INS and ICF International, 2012.

23 Moshiro C, Heuch I, Astrøm AN, et al. Injury morbidity in an urban and a rural area in Tanzania: an epidemiological survey. BMC Public Health 2005;5:11.

24 Olawale OA, Owoaje ET. Incidence and pattern of injuries among residents of a rural area in south-western Nigeria: a communitybased study. BMC Public Health 2007;7:246.

25 Naidoo KS, Jaggernath J, Ramson P, et al. The prevalence of selfreported vision difficulty in economically disadvantaged regions of South Africa. Afr J Disabil 2015;4:136.

26 Groen RS, Samai M, Petroze RT, et al. Pilot testing of a populationbased surgical survey tool in Sierra Leone. World J Surg 2012;36:771-4.

27 Gupta S, Ranjit A, Shrestha R, et al. Surgical needs of Nepal: pilot study of population based survey in Pokhara, Nepal. World J Surg 2014;38:3041-6.

28 Gupta S, Shrestha S, Ranjit A, et al. Conditions, preventable deaths, procedures and validation of a countrywide survey of surgical care in Nepal. Br J Surg 2015;102:700-7.

29 Eyler L, Hubbard A, Juillard C. Assessment of economic status in trauma registries: a new algorithm for generating population-specific clustering-based models of economic status for time-constrained low-resource settings. Int J Med Inform 2016;94:49-58.

30 Eyler L, Hubbard A, Juillard C. Optimization and validation of the EconomicClusters model for facilitating global health disparities research: examples from Cameroon and Ghana. PLoS One 2019;14:e0217197.

31 Schlag N, Zuzarte F. Market barriers to clean cooking fuels in subSaharan Africa: a review of literature. Stockholm, Sweden: Stockholm Environment Institute, 2008.

32 Harris PA, Taylor R, Thielke R, et al. Research electronic data capture (REDCap) - a metadata-driven methodology and workflow process for providing translational research informatics support. J Biomed Inform 2009;42:377-81.

33 StataCorp LP. Stata statistical software: release 14. College Station, TX: StataCorp LP, 2015.

34 Jaggernath J, Øverland L, Ramson P, et al. Poverty and eye health. Health 2014;06:1849-60.

35 Holden BA. Blindness and poverty: a tragic combination. Clin Exp Optom 2007;90:401-3.

36 The World Bank. Cameroon Economic Update, July 2013: Towards Greater Equity, A Special Focus on Health. Washington, DC: The World Bank, 2013

37 Okoroh JS, Chia V, Oliver EA, et al. Strengthening health systems of developing countries: inclusion of surgery in universal health coverage. World J Surg 2015;39:1867-74.

38 Oroxom R, Glassman A, McDonald L. Structuring and funding development impact bonds for health: nine lessons from Cameroon and beyond. Washington, DC: Center for Global Development, 2018. 